\title{
Influence of screw combination and nail materials in the stability of anterograde reamed intramedullary nail in distal femoral fractures
}

S. Gabarre ${ }^{1}$, J. Albareda ${ }^{2,3,4 \S}$, L.Gracia ${ }^{1,5}$, S. Puértolas ${ }^{1,5}$, E. Ibarz ${ }^{1,5}$, A. Herrera ${ }^{3,4}$

${ }^{1}$ Department of Mechanical Engineering, University of Zaragoza. Zaragoza, Spain

${ }^{2}$ Department of Orthopaedic Surgery and Traumatology, Lozano Blesa University

Hospital. Zaragoza, Spain

${ }^{3}$ Aragón Health Research Institute. Zaragoza, Spain

${ }^{4}$ Department of Surgery, University of Zaragoza. Zaragoza, Spain

${ }^{5}$ Aragón Institute for Engineering Research. Zaragoza, Spain

${ }^{\S}$ Corresponding author:

E-mail: $\quad$ albaredajorge@gmail.com

Address: $\quad$ Medicine School

University of Zaragoza

Domingo Miral, s/n

50009 - Zaragoza (SPAIN)

Email addresses:

SG : sergioga@unizar.es Sergio Gabarre

LG: lugravi@unizar.es Luis Gracia

SP: spb@unizar.es Sergio Puértolas

EI: eibarz@unizar.es Elena Ibarz

AH: antonio.herrera@unizar.es Antonio Herrera 


\section{ABSTRACT}

Intramedullary nailing (IM) is a technique universally accepted to treat femoral diaphyseal fractures. The treatment of distal fractures located in the distal third remains a controversial issue though. Thus there is a wrangle over the choice of method of fixation in fractures of the distal third of the femur.

A finite element model of the femur has been developed, analysing distal fractures with several gap sizes combined with different interlocking combinations of distal screws with one oblique screw proximally to stabilize the intramedullary nail. The mechanical strength of the nail against bending and compression efforts was studied comparing three materials for the nail: stainless-steel, titanium alloy and cobalt-chromiummolybdenum alloy.

Beside the FE simulations, a clinical follow-up was realized, considering a sample of 15 patients, 6 males and 9 females, with mean age of 53.2 years. Localizations of fractures were 10 in the right femur and 5 in the left femur, respectively.

A fairly good correspondence agreement between clinical results and the simulated fractures in terms of gap size was found. Non-comminuted fractures have a mean consolidation time of 20.5 weeks (4.8 months), which tendency corresponds to the mobility obtained in the FE simulations, whereas comminuted fractures have a higher mean consolidation period estimated in 22.2 weeks (5.2 months) corresponding to the excessive mobility at fracture site obtained by means of FE simulations.

Results associated with the different screw combinations exhibited the best stability at fracture site for the system with three distal screws and the system with two distal screws placed medial lateral. The highest leverage of distal screws is obtained maximizing the distance between them and choosing the coronal plane for their orientation. The results obtained with both nail materials (stainless steel and titanium alloy) show a higher mobility when using titanium nails. Steel nails provide stiffer osteosyntheses than the titanium nails. 
In conclusion, the best screw combination in terms of stability to produce fracture healing and the least difficulties during surgical procedure is the one which had one oblique proximal screw with two distal lateral screw implanted in the coronal plane.

Key terms: Intramedullary nail, Anterograde reamed nail, Femoral distal fracture, Screw combination analysis, Osteosynthesis, Finite element analysis. 


\section{1.-INTRODUCTION}

Intramedullary nailing (IM) is a technique universally accepted to treat femoral diaphyseal fractures, however the treatment of distal fractures located in the distal third remains a controversial issue

Distal femoral fractures account for $1 \%$ of fractures, and between 3-6\% of femoral fractures, the incidence increases with age [1,2]. There are two etiological possibilities in these fractures: a) young patients with injuries of high energy, and b) older patients, where a fall is able to produce fracture. It has been published a peak incidence in young women and older women [2,3]. Regularly, the mechanisms in both etiologic cases are comminuted. Within this group of fractures we must distinguish extra-articular fractures and fractures that affect the knee joint. Following the AO / OTA classification, we would have the type fractures A: extra- and intra-articular B and C [4].

Despite being extra-articular, there is controversy in the choice of method of fixation in fractures of the distal third of the femur, type A. The proposed methods are: anterograde or retrograde IM, Fixed-angle Blade Plate, Plate and Sliding Barrel Locking Condylar Plate [5].

The fundamental objectives of surgical treatment should be to ensure the stability of the fracture to achieve consolidation, keep the length and axis of the limb, get a good functional recovery, keeping the knee function, and all with an intervention aggressive surgical least possible [6].

We coincide with other authors, that it is possible to treat fractures in the area 5 of Wiss $[7,8]$ with anterograde locked IM [5, 6, 9, 10]. On the other hand, the locked IM is useful to stabilize supracondylar fractures with proximal extension to femoral diaphysis [9]. The advantages of locked IM, compared with other methods of osteosynthesis are: is a closed technique, preserves the hematoma in the focus of fracture, permits an easier extraction, exhibits a high rate of consolidation (98\%) and a low percentage of infection (1\%) [8]. 
Conversely, the new femoral nails allow multiple alternatives blocked lock distal to ensure the stability of the distal fragment, allowing anterograde extend the indications fastened it [6].

It is very important the minimum distance between the fracture site and the most proximal screw for distal fixation of the nail. Anterograde IM is possible when the fracture is located more than $3 \mathrm{~cm}$ from closest distal screw [11]. In vitro studies conducted by this author reported that an anterograde titanium alloy nail will survive 1 million compression/bending cycles when the fracture is $>$ or $=3 \mathrm{~cm}$ from the closest of the 2 distal locking screws. In these types of fractures, large-diameter nails should be used to avoid fatigue fracture at the screw holes [9, 12] furthermore distal cortical contact increase stability of the system [12].

It is difficult to accumulate enough number of fractures with different gap in the fracture site to enable us to implement different combinations of placement of distal screws and with nails of different alloy to draw conclusions about which is the ideal combination, so that an effective method is to use the simulation by Finite Elements. Computational techniques are considered to be a powerful, time-efficient and proven tool to reproduce biomechanical behaviour of a wide range of phenomena globally and locally.

Concerning finite element (FE) simulations a previous work developed by Shih [13] studied analyzed the influence of muscular contractions on stress analysis of distal nail holes and locking screws for different load conditions. As conclusion, when increasing the distance from the closest distal screw to the fracture site, a higher global mobility is obtained. In other work [14], three-dimensional nonlinear finite element models were developed, and the implant strength, fixation stability, and contact area of the fracture surfaces were evaluated and the results showed that the static fixation technique resulted in sufficient fixation stability and that the dynamic fixation techniques decreased the failure risk of the implant and produced a larger contact area of the fracture surfaces.

The objective of the present work is to determine the best screw combination for distal fractures with three gap sizes analysing different material for the nail for a given accidental load in the early post-operative stage, without considering the onset of 
biological process focussed on the fracture healing. Four locking screw combinations and two materials (stainless steel and titanium) were analysed.

\section{2.-MATERIALS \& METHODS}

\section{1.-Modelling of the femur and implants}

A three dimensional (3D) finite element model of the femur from 55 year old male donor was developed. Outer Geometry of the femur was obtained by means of 3D scanner Roland3D Roland ${ }^{\circledR}$ PICZA (Irvine, California) scanner, whereas a set of computed tomography (CT) of the donor's femur were treated using Mimics ${ }^{\circledR}$ Software (Materialise, Leuven). Once the inner interface between cortical and trabecular bone was determined, by means of an in-house algorithm material properties were assigned to the FE model in I-Deas [15], using the same workflow of a previous study [16].

The studied femoral nail Stryker S2 ${ }^{\mathrm{TM}}$ (Stryker, Mahwah, NJ, USA) was 380 mm long, with a wall thickness of $2 \mathrm{~mm}$ and an outer diameter of $13 \mathrm{~mm}$. This reamed anterograde nail uses locking screws of $5 \mathrm{~mm}$ of outer diameter, which were modelled as cylinders of the same diameter.

\section{2.-Meshing and material properties}

Nail surgery was reproduced in I-Deas in a virtual way, inserting the nail into the femur with the corresponding screws. Afterwards the assembly of the computer aided design (CAD) model was performed under surgeon supervision. Bone, nail and screws were meshed with linear tetrahedron. They were assumed for the bone linear elastic isotropic properties $\left(\mathrm{E}_{\text {Cortical }}=20000 \mathrm{MPa}, \mathrm{n}=0.3 ; \mathrm{E}_{\text {Trabecular }}=959 \mathrm{MPa}, \mathrm{n}=0.3\right.$ [17], as reference), with variable values related with the processed CT images. The metallic nail was made either 316 LVM steel $(E=192.36 \mathrm{GPa}, \nu=0.3)$ or Ti-6L-4V $(\mathrm{E}=113.76 \mathrm{GPa}, \nu=0.34)$ or Cobalt-Chromium-Molybdenum (CoCrMb) $(\mathrm{E}=214 \mathrm{GPa}, \nu=0.3)$ and metallic screws of 316 LVM steel, both assumed to be linear elastic isotropic. 
A sensitivity analysis was performed to determine the minimal size mesh required for an accurate simulation. For this purpose, a mesh refinement was performed in order to achieve a convergence towards a minimum of the potential energy, both for the whole model and for each of its components, with a tolerance of $1 \%$ between consecutive meshes.

\section{3.- Configurations used and contact modelling}

The purpose of this study was to investigate de optimal screw combination for a single distal fracture location and gap size. The transverse fracture was modelled using an irregular surface remaining faithfully to a comminuted fracture considering three gap sizes: $0.5 \mathrm{~mm}, 3 \mathrm{~mm}$ and $20 \mathrm{~mm}$. Thus, four combinations of locking screws were considered as Table 1 shows: one oblique proximal screw combined with four configurations of the three distal ones, two lateral-medial (L/M) and one anteroposterior (A/P). Table 1 summarizes the list of FE models simulated for the three gap sizes: 4 models were generated for each material of the nail.

The present was study considered the immediate post-operative stage. Consequently, no biological osseointegration process was considered. Contact interaction was assumed between the outer surface of the nail and the inner cortex of the medullary canal of the femur (Fig. 1). Tied interaction between screws and cortical bone was considered, whereas contact between screws a femoral nail was simulated. The selected friction values of bone/nail and nail/screws were 0.1 and 0.15 , respectively, in accordance with literature [18-20]. Other similar studies modelled bone/nail interaction as frictionless, though $[21,22]$.

\section{4.- Loads and boundary conditions}

Regarding boundary conditions for all the simulations, fully constrained conditions at the condyles were considered and a load case associated with an accidental support of the leg at early post-operative (PO) stage (Fig. 2). This load was quantified to be about $25 \%$ the maximum gait load. According to Orthoload's database, the hip reaction force and abductor force (as the prime muscle group), referred to the $45 \%$ of gait, correspond 
to the maximum and most representative load [23]. Muscle attachments areas corresponding to abductor group muscle were determined mimicking anatomy atlas.

\section{5.- Clinical follow-up}

Beside the FE simulations, a clinical follow-up was realized, considering a sample of 15 patients, 6 males and 9 females, with mean age of 53.2 years, all of them treated with anterograde femoral nail Stryker $\mathrm{S} 2{ }^{\mathrm{TM}}$. Localizations of fractures were 10 in the right femur and 5 in the left femur. The statistic corresponding to fracture localization and fracture grade are included in Table 2. The comminute grade was measured according to the scale of Winquist/Hansen [24]. For all the clinical cases, the interlocking systems correspond to the fourth one (Table 1): one proximal oblique screw and two distal screws places in lateral-medial position.

\section{3.-RESULTS}

The FE simulations allow obtaining the mobility results for the different cases analyzed. Figure 3 shows the deformed shape amplified (x25) and the vertical displacement maps (U3) corresponding to all four combinations of screws and steel nail.

The study of micromotions at fracture site was measured as the relative motion between pairs of homologue points defined from opposed nodes depicted in Fig. 4. When analysing micromotions at fracture site in order to investigate fracture healing according to Perren's method [15], models with gap sizes of $3 \mathrm{~mm}$ and $20 \mathrm{~mm}$ verify this condition as Table 3a and 3b show for both materials of the nail. The threshold strain value of $10 \%$ beyond which fracture healing is expected to occur strongly depends on the gap size. Values for steel nail range from $1.61 \%$ to $2.06 \%$ and $0.33 \%$ to $0.41 \%$ for gap sizes of $3 \mathrm{~mm}$ and 20 respectively. Values for titanium nail are incremented due to the smaller stiffness of the complete locking mechanism with values 3.06 \%-3.36\% for $3 \mathrm{~mm}$ gap size and $0.62 \%-0.48 \%$ for $20 \mathrm{~mm}$ gap size.

Conversely, except from the fourth screw combination (8.14\%), all models with gap size of $0.5 \mathrm{~mm}$. and steel nail produce strains beyond the proposed threshold (10.91$11.05 \%$ ), none of them verify Perren's conditions when changing material nail. These 
obtained results for the smallest gap could be counterintuitive as the biggest fracture gives strains below the $10 \%$ threshold. Consequently, this criterion should be used with caution.

The maximum amplitude of micromotion between homologue points at the fracture site for steel and titanium nail is reported in Tables $4 \mathrm{a}$ and $4 \mathrm{~b}$ respectively. The most rigid behaviour both nail materials corresponds to the fourth interlocking system: $40.69 \mu \mathrm{m}$ (gap size of $0.5 \mathrm{~mm}$ ) and $48.33 \mu \mathrm{m}$ (gap size of $3 \mathrm{~mm}$ ), whereas the first one (three distal screws) shows the best stability in terms of micromotions for biggest gap size of $20 \mathrm{~mm}$ : $63.50 \mu \mathrm{m}$. The second and the third screw combination exhibit a similar behaviour when the nail material is changed to titanium and among the three gap sizes.

Tables $5 \mathrm{a}$ and $5 \mathrm{~b}$ show the global stability of each fixation system which follows similar tendencies as the aforementioned amplitude of micromotion for steel nail and titanium nail. The global movement at the top of the nail was measured yielding to the most rigid behaviour for the fourth interlocking system: 1.75 to $2.01 \mathrm{~mm}$ for steel nail whereas for titanium nail, the first screw combination showed smallest motion for the first interlocking system $2.81 \mathrm{~mm}$ and $2.80 \mathrm{~mm}$ (3 mm gap size and $20 \mathrm{~mm}$ respectively). For the smallest gap size, the fourth interlocking system was again the most stable in terms of global movement $(2.36 \mathrm{~mm})$. Analogously to the analyzed micromotions, the second and the third fixation system yield to similar results for both materials in the two gaps associated with comminuted fractures.

Table 6a summarizes the evolution of micromotion at fracture site associated to the fourth interlocking system for different nail materials and fracture gap sizes. Table $6 \mathrm{~b}$ compiles results associated to global stability. A marked tendency is reported in these tables showing a decrease in mobility (global and local) from titanium to CoCrMb. Results of stability for every type of fracture are similar for steel and CoCrMb, while the stability decreases for titanium nail.

With respect to the clinical follow-up, non-comminuted fractures have a mean consolidation time of 20.5 weeks (4.8 months), whereas comminuted fractures (grade 2 and 1 Winquist and Hansen) have a higher mean consolidation period estimated in 22.2 weeks (5.2 months). One case resulted in pseudarthrosis with is posterior surgery. 


\section{4.-DISCUSSION}

The choice of method of surgical treatment to stabilize the extra-articular fractures of the lower third of the femur remains a controversial issue but the appearance of new blocked nails, can extend the indication of anterograde nailing this type of fractures [25]. Fracture healing may be modified by extrinsic conditions, one of the most important is biomechanics of fracture fixation [26] Achieve good stability of the fracture site is essential for the consolidation. This stability is determined by several factors including nail size, number of locking screws or bolts, and distance of the locking screw or bolt from the fracture site [27].

The originality of our work is that from our knowledge no simulation studies on the influence on the stability of fracture site depending on the number and orientation of the distal locking screws using different alloys of material with different gap of fracture site. The use of computational techniques has been an excellent tool to verify whether the stability provided by different interlocking systems consistent with the achievement of the consolidation in case of comminuted distal femoral fractures.

In the locked intramedullary the load is transmitted from proximal to distal to the distal screws, which are subjected to high stress. This stress of distal screw decreased as the length of nail-cortical contact and the distance between the distal locking screw and the fracture site increased [28]. The diameter of the nail is important in fractures of the distal third to ensure good contact with the femoral medial cortex and also to allow the insertion of locking screws minimum diameter of $5 \mathrm{~mm}$, we have employed in the simulation a nail of $13 \mathrm{~mm}$ section and screws $5 \mathrm{~mm}$.

Works have been published on the safety lock that gives a static screw [14]. The need to place 2 distal screws in titanium nails [29].

Variations in the stress of the distal screws in relation with the distance between the fracture site and distal locking screws [28]. The influence on stability with a single distal static screw relating it to the distance of the screw to fracture site [30] and 
checking that can significantly affect rotational stability but not axial or angular fixation. The security that can give set screws use as distal locking [31].

It is accepted that the position of the proximal locking screws is in different biomechanical point of view , but two screws should be placed [25]. Interestingly there are works about the position and number of distal screws in the tibial nailing [32-34]. However there are no biomechanical studies about the influence on stability according to the number and orientation of the distal screws, so we consider our study interesting and original.

According to the results presented previously, Perren's method can be a useful verification for fracture healing when evaluating small gap sizes due to the strong dependence of the strain value with the analyzed gap size. Therefore, counterintuitive results are obtained, as the biggest fracture gives strains below the $10 \%$ threshold compared to gaps sizes of $0.5 \mathrm{~mm}$ and $3 \mathrm{~m}$. Consequently, this criterion should be used with caution.

The stability at fracture site measured in terms of relative micromotions of homologue points provides a more accurate measure for bone ingrowth. Evaluating results obtained for steel nail, the fourth interlocking system produce the best results in terms of local and also global stability for non-comminuted fractures; for comminuted fractures the first and the fourth interlocking systems provide the same stability. On the other hand, for titanium nail, the best results were obtained for the fourth interlocking system for the minimum gap $(0.5 \mathrm{~mm})$; for the intermediate gap $(3.0 \mathrm{~mm})$, the first and the fourth interlocking systems provide similar stability; finally, for comminuted fractures, the first interlocking system achieve the best results.

The highest locking rate is achieved when the distance between distal screws bigger, as the lever arm produced to block the movement of the nail is higher. Thereupon, the use of screw \#3 for the first locking model is not leveraged and thus, micromotions produced by the second and third interlocking systems are within the same high rate as the distance between both distal screws is minimal. Besides, the inclusion of a third screw in a different plane (antero posterior) does not improve results compared to two L/M locking system. Thus, this A/P does not account for the extra difficulties assigned 
to the surgical technique: longer surgery times, higher radiation exposition and bigger difficulties associated to the screw insertion in two anatomical planes (sagittal and coronal). Therefore an alternative design of the nail can be proposed to maximize the distance of $\mathrm{L} / \mathrm{M}$ threads with the restrictions of proximity to distal fracture and femoral condyles.

From analyzed results comparing the three materials used for the nails, the election of steel nail prevails over the election of the thread combination, whereas for titanium nail screw combination plays the most important role. This is even more marked for comminuted fractures (gap size of $20 \mathrm{~mm}$ ). Considering a stiffer material for the nail as CoCrMb alloy for the fourth model, the aforementioned tendency is confirmed as the behaviour of global motion and micromotions are more uniform between CoCrMb and Steel nail for gap sizes of 0.5 and $3 \mathrm{~mm}$. On the other hand, when the stiffness of nail is reduced with titanium, stability is reduced considerably even more for gap size of 20 $\mathrm{mm}$ where it plummets. Titanium nail does not confer the same stiffness to the fractured femur as the steel nail, globally and at fracture site.

The correspondence of clinical results with simulations is although fairly good, they are not conclusive, as the number of patients is slightly small. In addition to this, the concept of consolidation is normally under debate, as it is defined according to clinical criteria related with symptomatology and interobserver radiological procedures.

\section{5.-CONCLUSIONS}

FE models developed in the present work permitted characterize the stability of different interlocking systems and identify the optimal one for every type of fracture. Moreover, the results are in correspondence to a set of clinical cases included in the follow-up.

Non-comminuted fractures have the minimum mean consolidation time, which coincides with the appropriate mobility at fracture site obtained in the FE simulations, whereas comminuted fractures have the higher mean consolidation period, 
corresponding to the excessive mobility at fracture site obtained by means of $\mathrm{FE}$ simulations. The healing time increases inasmuch as the comminution grade is higher.

Among the studied combinations of distal screws, the one with two distal screws medial lateral provided the best results in terms of stability at fracture site and global movement at the top of the nail along the three fracture gaps sizes. This tendency is explained as the locking effect is maximized when the distance in between the distal screws is increased. This parameter is limited by the proximity to fracture site and the distance to femoral condyles. Mobility rate with titanium screw was higher than with steel nail as it confers a stiffer fixation system which is better for osteosynthesis.

Although a fair agreement between clinical results and the simulated fractures is obtained, this correspondence should be taken with caution as set of patients is small and consolidation is a blurred concept.

In conclusion, the best screw combination in terms of stability to produce fracture healing and the least difficulties during surgical procedure is the one which had one oblique proximal screw with two distal lateral screw implanted in the coronal plane.

\section{List of abbreviations used}

IM: Intramedullary Nailing

FE: Finite Element

3D: Three-Dimensional

CT: Computed Tomography

CAD: Computed Aided Design

CoCrMb: Cobalt-Chromium-Molybdenum

L/M: Lateral-medial

A/P: Antero-posterior

PO: Pos-operative

\section{Authors' contributions}

AH, JA and LG conceived the design of study. LG, SG, EI and SP conceived and developed the finite element models and carried out all the simulations. AH and JA 
realized the medical supervision of models. All authors participated in the drawing up of the manuscript, and read and approved the final manuscript.

\section{Acknowledgements}

This research has been partially financed by The Fundacion Mutua Madrileña (Research Projects: AP162632016) and by the Government of Spain: Ministry of Economy and Competitiveness (Research Project: DPI2016-77745-R).

\section{Competing interests}

None declared

\section{References}

1. Court-Brown CM and Caesar B, Epidemiology of adult fractures: A review. Injury 2006;37: 691-7.

2. Martinet O, Cordey J, Harder Y, Maier A, Buhler M, and Barraud GE, The epidemiology of fractures of the distal femur. Injury 2000;31 Suppl 3: C62-3.

3. Arneson TJ, Melton LJ, 3rd, Lewallen DG, and O'Fallon WM, Epidemiology of diaphyseal and distal femoral fractures in Rochester, Minnesota, 1965-1984. Clin Orthop Relat Res 1988: 188-94.

4. Marsh JL, et al., Fracture and dislocation classification compendium - 2007: Orthopaedic Trauma Association classification, database and outcomes committee. $J$ Orthop Trauma 2007;21: S1-133.

5. Ehlinger M, Ducrot G, Adam P, and Bonnomet F, Distal femur fractures. Surgical techniques and a review of the literature. Orthop Traumatol Surg Res 2013;99: 35360.

6. Gwathmey FW, Jr., Jones-Quaidoo SM, Kahler D, Hurwitz S, and Cui Q, Distal femoral fractures: current concepts. J Am Acad Orthop Surg 2010;18: 597-607.

7. Wiss DA, Fleming CH, Matta JM, and Clark D, Comminuted and rotationally unstable fractures of the femur treated with an interlocking nail. Clin Orthop Relat Res 1986: 35-47.

8. $\quad$ Winquist RA, Locked Femoral Nailing. J Am Acad Orthop Surg 1993;1: 95-105.

9. $\quad$ Albert MJ, Supracondylar Fractures of the Femur. J Am Acad Orthop Surg 1997;5: 163-171.

10. Kulkarni SG, Varshneya A, Kulkarni GS, Kulkarni MG, Kulkarni VS, and Kulkarni RM, Antegrade interlocking nailing for distal femoral fractures. J Orthop Surg (Hong Kong) 2012;20: 48-54.

11. Antekeier SB, Burden RLJ, Voor MJ, and Roberts CS, Mechanical Study of the Safe Distance Between Distal Femoral Fracture Site and Distal Locking Screws in Antegrade Intramedullary Nailing. Journal of Orthopaedic Trauma 2005;19: 693-697.

12. Huang SC, Lin CC, and Lin J, Increasing nail-cortical contact to increase fixation stability and decrease implant strain in antegrade locked nailing of distal femoral fractures: a biomechanical study. J Trauma 2009;66: 436-42.

13. Shih KS, Tseng CS, Lee CC, and Lin SC, Influence of muscular contractions on the stress analysis of distal femoral interlocking nailing. Clinical Biomechanics 2008;23: 38-44. 
14. Shih KS, Hsu CC, Hsu TP, Hou SM, and Liaw CK, Biomechanical analyses of static and dynamic fixation techniques of retrograde interlocking femoral nailing using nonlinear finite element methods. Computer Methods and Programs in Biomedicine 2014;113: 456-464.

15. Siemens, $\quad I$-deas ${ }^{\circledR} \quad 11 \quad N X \quad$ Series $\quad P L M \quad$ software [http://www.plm.automation.siemens.com/] 2013: Plano (Texas).

16. Gabarre S, Herrera A, Mateo J, Ibarz E, Lobo-Escolar A, and Gracia L, Study of the polycarbonate-urethane/metal contact in different positions during gait cycle. Biomed Res Int 2014;2014: 548968.

17. Herrera A, Panisello JJ, Ibarz E, Cegonino J, Puertolas JA, and Gracia L, Long-term study of bone remodelling after femoral stem: A comparison between dexa and finite element simulation. Journal of Biomechanics 2007;40: 3615-3625.

18. Grant JA, Bishop NE, Gotzen N, Sprecher C, Honl M, and Morlock MM, Artificial composite bone as a model of human trabecular bone: the implant-bone interface. $J$ Biomech 2007;40: 1158-64.

19. Eberle S, Gerber C, von Oldenburg G, Hungerer S, and Augat P, Type of Hip Fracture Determines Load Share in Intramedullary Osteosynthesis. Clinical Orthopaedics and Related Research 2009;467: 1972-1980.

20. Chen SH, Chiang MC, Hung CH, Lin SC, and Chang HW, Finite element comparison of retrograde intramedullary nailing and locking plate fixation with/without an intramedullary allograft for distal femur fracture following total knee arthroplasty. Knee 2014;21: 224-31.

21. Samiezadeh S, Tavakkoli Avval P, Fawaz Z, and Bougherara H, Biomechanical assessment of composite versus metallic intramedullary nailing system in femoral shaft fractures: A finite element study. Clin Biomech 2014;29: 803-10.

22. Montanini R and Filardi V, In vitro biomechanical evaluation of antegrade femoral nailing at early and late postoperative stages. Medical Engineering \& Physics 2010;32: 889-897.

23. Villavicencio AT, Burneikiene S, Bulsara KR, and Thramann JJ, Perioperative complications in transforaminal lumbar interbody fusion versus anterior-posterior reconstruction for lumbar disc degeneration and instability. J Spinal Disord Tech 2006;19: 92-7.

24. Winquist RA and Hansen ST, Jr., Comminuted fractures of the femoral shaft treated by intramedullary nailing. Orthop Clin North Am 1980;11: 633-48.

25. Bong MR, Kummer FJ, Koval KJ, and Egol KA, Intramedullary nailing of the lower extremity: biomechanics and biology. J Am Acad Orthop Surg 2007;15: 97-106.

26. Kwong FN and Harris MB, Recent developments in the biology of fracture repair. $J$ Am Acad Orthop Surg 2008;16: 619-25.

27. Brumback RJ, Toal TR, Jr., Murphy-Zane MS, Novak VP, and Belkoff SM, Immediate weight-bearing after treatment of a comminuted fracture of the femoral shaft with a statically locked intramedullary nail. J Bone Joint Surg Am 1999;81: 1538-44.

28. Lin J, Lin SJ, Chen PQ, and Yang SH, Stress analysis of the distal locking screws for femoral interlocking nailing. J Orthop Res 2001;19: 57-63.

29. Im GI and Shin SR, Treatment of femoral shaft fractures with a titanium intramedullary nail. Clin Orthop Relat Res 2002: 223-9.

30. George CJ, Lindsey RW, Noble PC, Alexander JW, and Kamaric E, Optimal location of a single distal interlocking screw in intramedullary nailing of distal third femoral shaft fractures. J Orthop Trauma 1998;12: 267-72.

31. Kose N, Gunal I, Wang X, Athanasiou KA, Agrawal CM, and Mabrey JD, Setscrew distal locking for intramedullary nails: a biomechanical study. J Orthop Trauma 2000;14: 414-9.

32. Henley MB, Meier M, and Tencer AF, Influences of some design parameters on the biomechanics of the unreamed tibial intramedullary nail. J Orthop Trauma 1993;7: 311-9. 
33. Laflamme GY, Heimlich D, Stephen D, Kreder HJ, and Whyne CM, Proximal tibial fracture stability with intramedullary nail fixation using oblique interlocking screws. $J$ Orthop Trauma 2003;17: 496-502.

34. Chen AL, Tejwani NC, Joseph TN, Kummer FJ, and Koval KJ, The effect of distal screw orientation on the intrinsic stability of a tibial intramedullary nail. Bull Hosp Jt Dis 2001;60: 80-3. 


\section{Figure legends}

Figure 1. Interaction between nail and bone and between screws and nail

Figure 2. Boundary conditions

Figure 3. Deformed shape (x25) and vertical displacement maps corresponding to a

distal fracture: a) $1^{\text {st }}$ interlocking system; b) $2^{\text {nd }}$ interlocking system; c) $3^{\text {rd }}$ interlocking system; d) $4^{\text {th }}$ interlocking system

Figure 4. Homologue points for micromotion processing: anterior and posterior view. 
Tables

Table 1. List of FE models according screw combination

\begin{tabular}{|c|c|c|c|c|}
\hline Model & $\begin{array}{c}\text { Proximal } \\
\text { screws }\end{array}$ & Distal screws & $\begin{array}{c}\text { Fracture } \\
\text { location }\end{array}$ & Gap size \\
\hline 1 & & $\begin{array}{c}2 \mathrm{M} / \mathrm{L} \text { screws } \\
\text { and } 1 \mathrm{~A} / \mathrm{P} \\
\text { screw }(\# 2,3,4)\end{array}$ & & $0.5 \mathrm{~mm}$. \\
\hline 2 & & $\begin{array}{l}1 \mathrm{~L} / \mathrm{M} \text { screw } \\
\text { and } 1 \mathrm{~A} / \mathrm{P} \\
\text { screw }(\# 2,3)\end{array}$ & 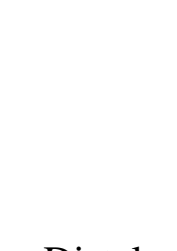 & \\
\hline 3 & & $\begin{array}{l}1 \mathrm{~L} / \mathrm{M} \text { screw } \\
\text { and } 1 \mathrm{~A} / \mathrm{P} \\
\text { screw }(\# 3,4)\end{array}$ & & $3 \mathrm{~mm}$. \\
\hline 4 & & $\begin{array}{c}2 \text { L/M screws } \\
(\# 2,4)\end{array}$ & & $20 \mathrm{~mm}$. \\
\hline
\end{tabular}

Table 2. Statistics for the clinical follow-up

\begin{tabular}{cccc}
\hline Wiss zone & Cases & Conminution grade & Cases \\
\hline 5 & 9 & None & 9 \\
\hline 5 & 5 & 2 & 5 \\
\hline 5 & 1 & 4 & 1 \\
\hline Total & & & 15 \\
\hline
\end{tabular}


Table 3a. Gap strain (\% $\varepsilon$ ) verification according to Perren. Steel nail

\begin{tabular}{cccc}
\hline \# Model & Gap 0.5 mm & Gap 3.0 mm. & Gap 20.0 mm. \\
\hline 1 & 10.91 & 2.06 & 0.32 \\
2 & 11.05 & 2.10 & 0.41 \\
3 & 10.93 & 2.20 & 0.41 \\
4 & 8.14 & 1.61 & 0.33 \\
\hline
\end{tabular}

Table 3b. Gap strain (\% $(\%)$ verification according to Perren. Titanium nail

\begin{tabular}{cccc} 
\# Model & Gap 0.5 mm & Gap 3.0 mm. & Gap 20.0 mm. \\
\hline 1 & 16.67 & 3.16 & 0.48 \\
2 & 16.90 & 3.22 & 0.63 \\
3 & 16.76 & 3.36 & 0.63 \\
4 & 12.40 & 3.06 & 0.62 \\
\hline
\end{tabular}

Table 4a. Amplitude of axial micromotion $[\mu \mathrm{m}]$. Steel nail

\begin{tabular}{cccc}
\hline \# Model & Gap 0.5 mm & Gap 3.0 mm. & Gap 20.0 mm. \\
\hline 1 & 54.53 & 61.73 & 63.50 \\
2 & 55.26 & 63.13 & 81.70 \\
3 & 54.64 & 66.14 & 81.24 \\
4 & 40.69 & 48.33 & 66.43 \\
\hline
\end{tabular}

Table 4b. Amplitude of axial micromotion $[\mu \mathrm{m}]$. Titanium

\begin{tabular}{cccc}
\hline \# Model & Gap 0.5 mm & Gap 3.0 mm. & Gap 20.0 mm. \\
\hline 1 & 83.34 & 94.95 & 96.28 \\
2 & 84.52 & 96.56 & 123.47 \\
3 & 83.80 & 100.69 & 126.54 \\
4 & 62.02 & 91.87 & 123.71 \\
\hline
\end{tabular}


Table 5a. Global movement at the top of the nail [mm]. Steel nail

\begin{tabular}{cccc}
\hline \# Model & Gap $0.5 \mathrm{~mm}$ & Gap $3.0 \mathrm{~mm}$. & Gap 20.0 mm. \\
\hline 1 & 1.89 & 2.07 & 2.03 \\
2 & 1.91 & 2.08 & 2.22 \\
3 & 1.90 & 2.13 & 2.52 \\
4 & 1.75 & 1.85 & 2.01 \\
\hline
\end{tabular}

Table 5b. Global movement at the top of the nail [mm]. Titanium nail

\begin{tabular}{cccc}
\hline \# Model & Gap 0.5 mm & Gap 3.0 mm. & Gap 20.0 mm. \\
\hline 1 & 2.59 & 2.81 & 2.80 \\
2 & 2.61 & 2.87 & 3.15 \\
3 & 2.60 & 2.94 & 3.50 \\
4 & 2.36 & 2.85 & 3.14 \\
\hline
\end{tabular}

Table 6a. Amplitude of axial micromotion $[\mu \mathrm{m}]$ for the \#4 model. Material nail:

Titanium, Steel and Cobalt-Chromium

\begin{tabular}{cccc}
\hline Material & Gap 0.5 mm & Gap 3.0 mm. & Gap 20.0 mm. \\
\hline CoCr & 37.22 & 44.31 & 60.65 \\
Steel & 40.69 & 48.33 & 66.43 \\
Titanium & 62.02 & 91.87 & 123.71 \\
\hline
\end{tabular}

Table 6b. Global Global movement at the top of the nail [mm] for the \#4 model.

Material nail: Titanium, Steel and Cobalt-Chromium

\begin{tabular}{cccc}
\hline Material & Gap $0.5 \mathrm{~mm}$ & Gap $3.0 \mathrm{~mm}$. & Gap $20.0 \mathrm{~mm}$. \\
\hline CoCr & 1.65 & 1.73 & 1.87 \\
Steel & 1.75 & 1.85 & 2.01 \\
Titanium & 2.36 & 2.85 & 3.14 \\
\hline
\end{tabular}




\section{Figures}

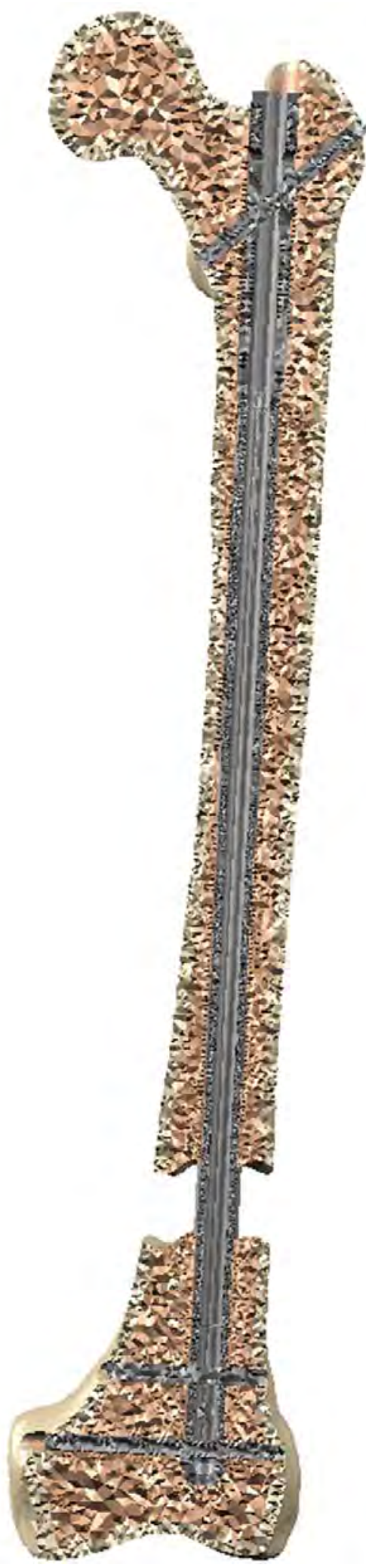

Figure 1. Interaction between nail and bone and between screws and nail 


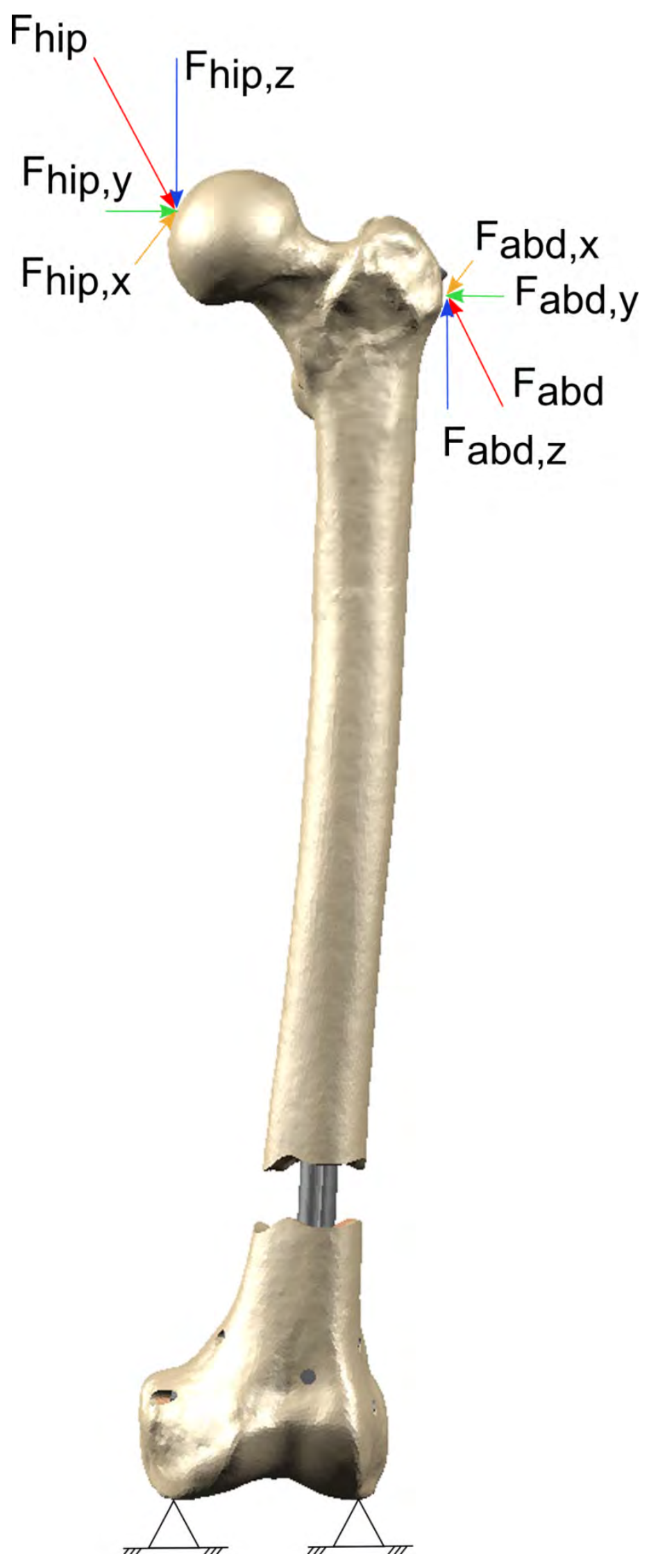

Figure 2. Boundary conditions 

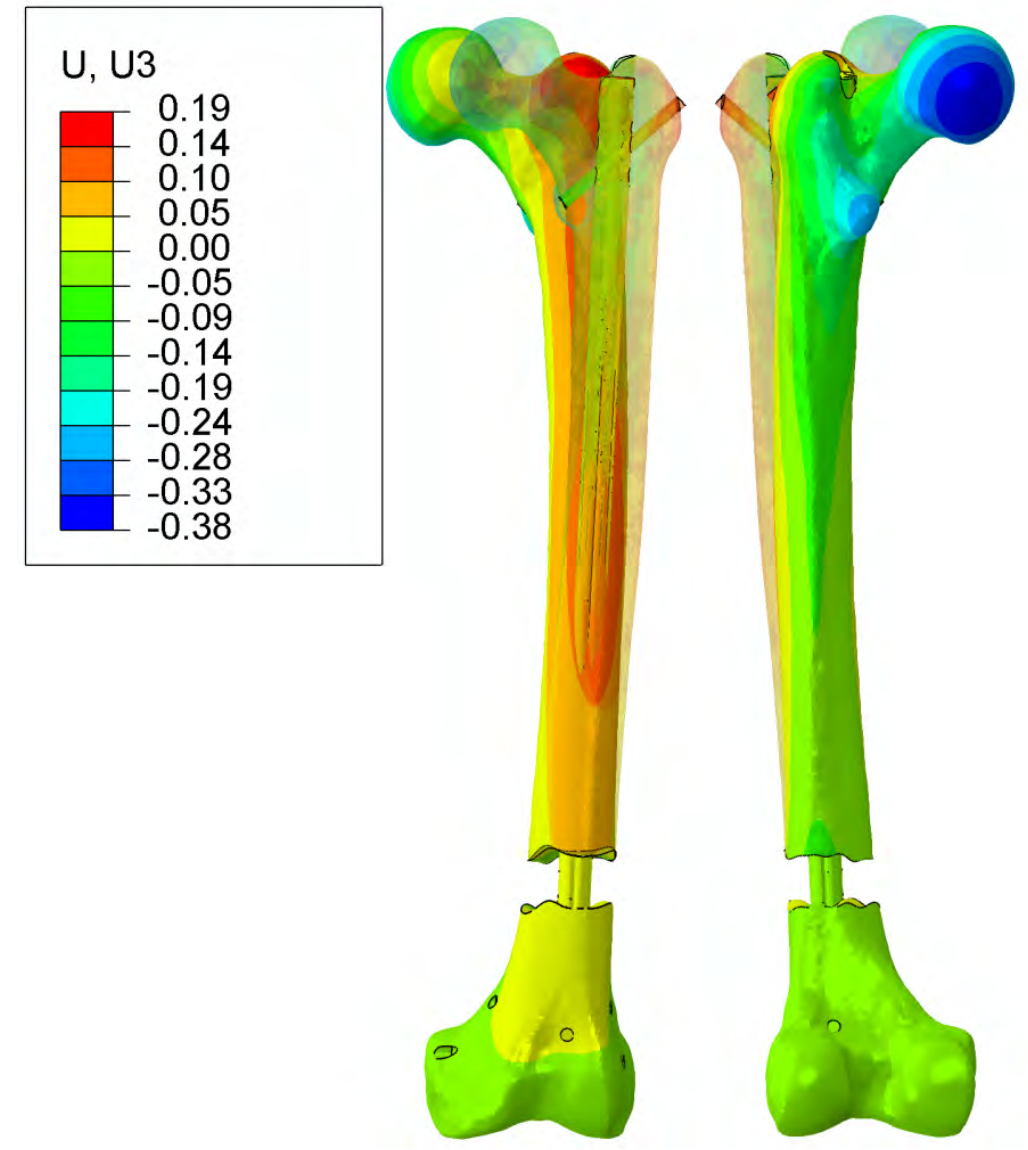

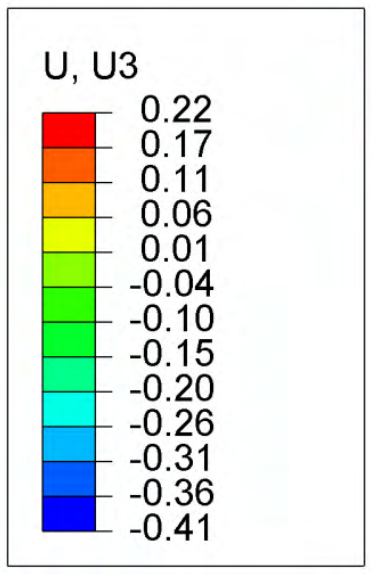

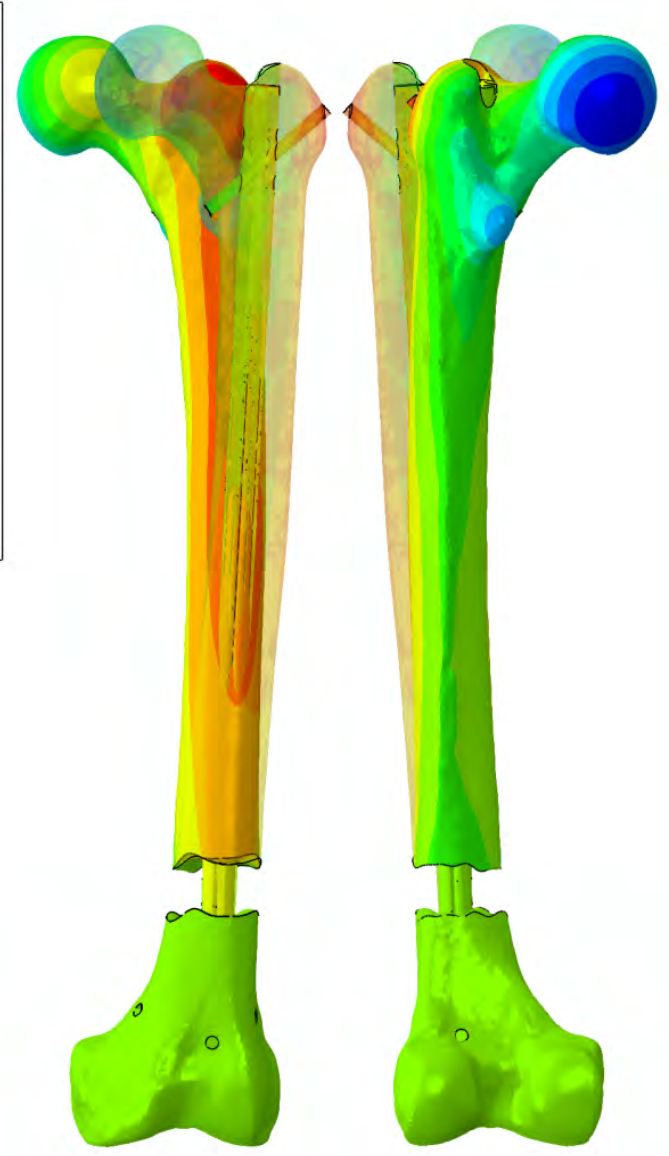



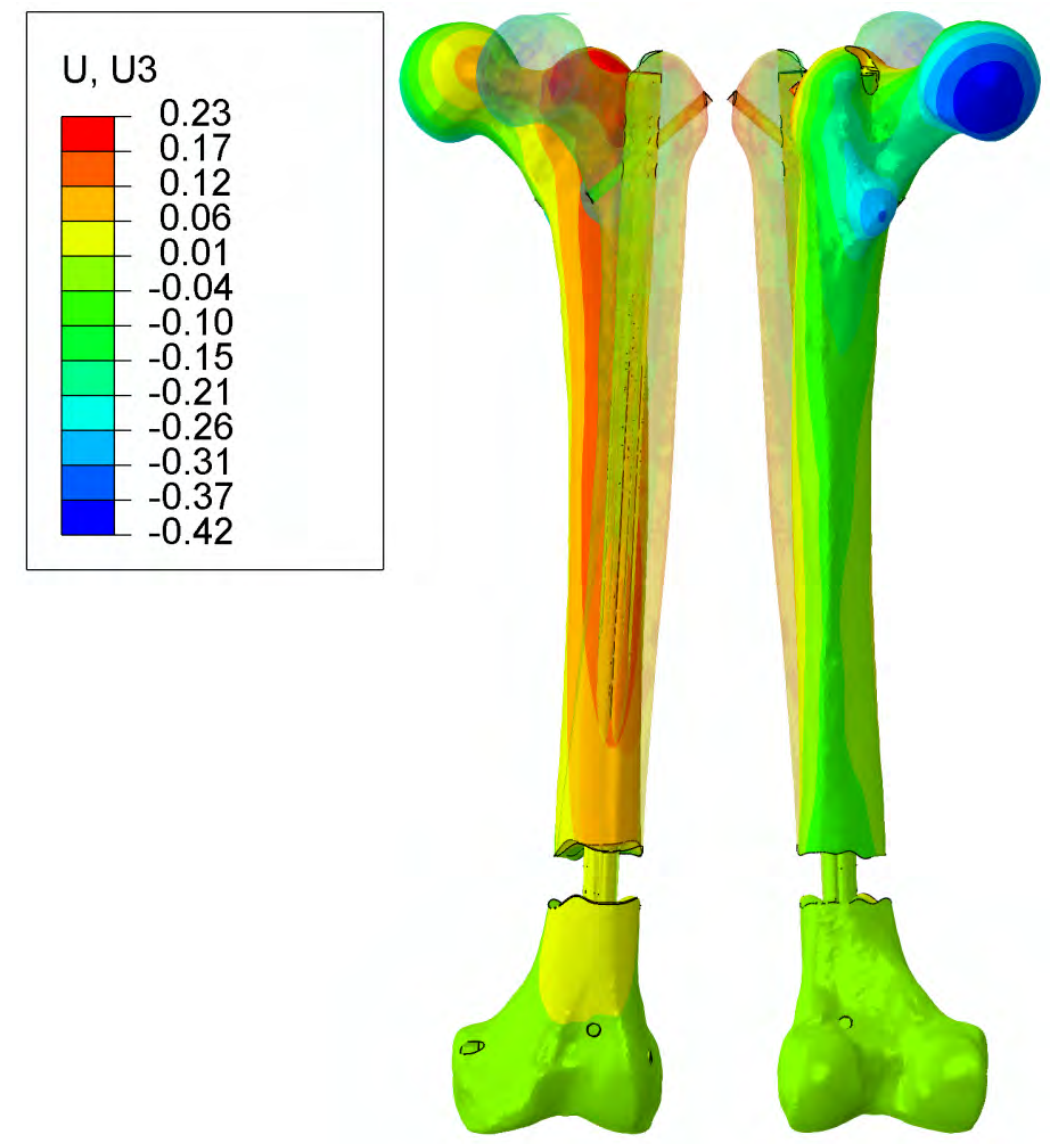

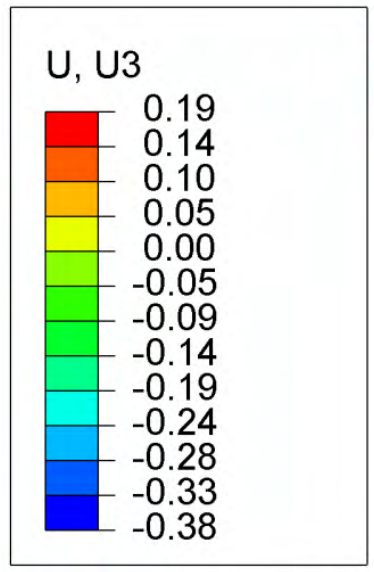

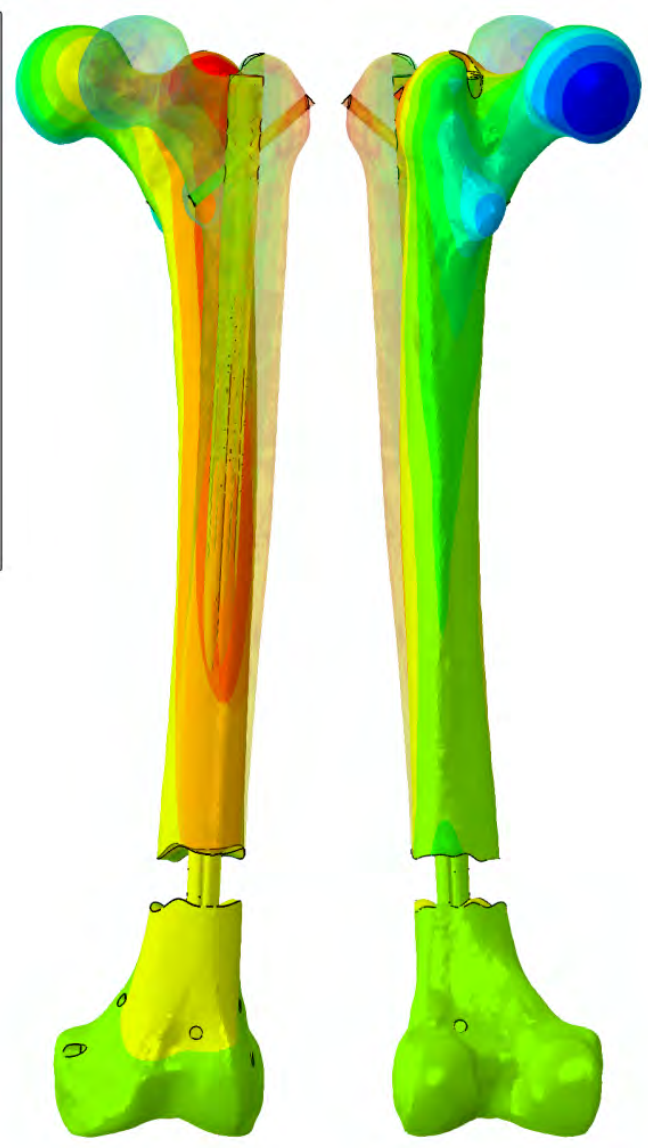


Figure 3. Deformed shape (x25) and vertical displacement maps corresponding to a distal fracture: a) $1^{\text {st }}$ interlocking system; b) $2^{\text {nd }}$ interlocking system; c) $3^{\text {rd }}$ interlocking system; d) $4^{\text {th }}$ interlocking system
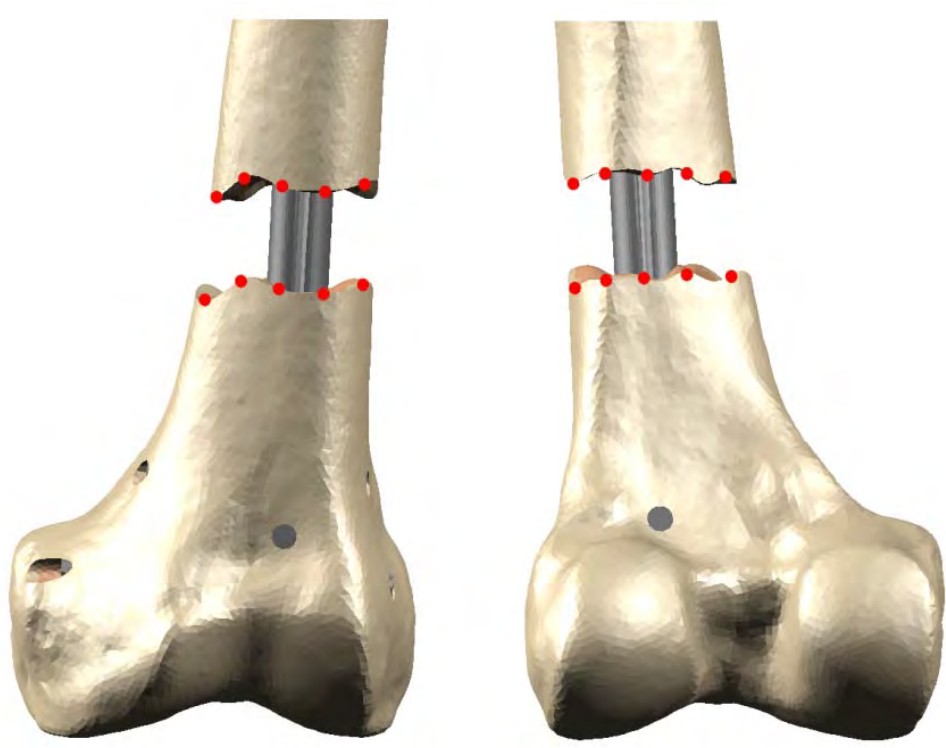

Figure 4. Homologue points for micromotion processing: anterior and posterior view. 